\title{
The automatic management of drivers and driving spaces
}

\author{
Martin Dodge ${ }^{\mathrm{a}, *}$, Rob Kitchin ${ }^{\mathrm{b}}$ \\ ${ }^{a}$ Geography, School of Environment and Development, University of Manchester, Oxford Road, Manchester M13 9PL, United Kingdom \\ ${ }^{\mathrm{b}}$ NIRSA, National University of Ireland, Maynooth, Co. Kildare, Ireland
}

Received 22 November 2005; received in revised form 18 July 2006

\begin{abstract}
In this paper, we examine the development and implementation of new technical systems designed to more effectively manage and produce driving, drivers and driving spaces. These new systems change the governmentality of automobilities by altering the relationship between driver, vehicle and transport infrastructure and produce new subjects and spaces. They do this principally through the process of automation, creating a system of regulation that we term 'automated management'. Automated management consists of two interlocking sets of regulatory technologies: automated surveillance that seeks to enforce more effective (self)disciplining and capture systems that actively reshape activity. We argue that these work together to alter the automobilities landscape creating new sociospatial arrangements with respect to access, movement, flow, and behaviour. Some of these arrangements are benign and empowering to individuals, others enhance the power of state and corporations. We illustrate our argument with examples predominately drawn from the UK, though the technologies we discuss are increasingly being developed and implemented throughout Western countries and beyond.
\end{abstract}

(C) 2006 Elsevier Ltd. All rights reserved.

Keywords: Automobile; Software; Surveillance; Space; Transport

\section{Highway codes}

Over the past 30 years, the practices of everyday life have become increasingly infused with and mediated by software. Whatever the task - domestic living, working, consuming, travelling or communicating - software increasingly makes a difference to how everyday life takes place. Software is embedded into objects and systems as a means to enhance and manage usage and is pivotal in linking together disparate and distributed infrastructures. It also enables new and refined processes, for example through the generation, storage, profiling, screening and

\footnotetext{
${ }^{*}$ Corresponding author.

E-mail addresses: m.dodge@manchester.ac.uk (M. Dodge), rob.kitchin @ nuim.ie (R. Kitchin).
}

communication of capta ${ }^{1}$ about individuals, objects, information, transactions, and territories (Dodge and Kitchin, 2005a). Importantly, software has profound spatial effects, both through the automatic production of space that generates new spatialities (Thrift and French, 2002; Dodge and Kitchin, 2005b) and the creation of software-sorted (Graham, 2005) or machine readable (Dodge and Kitchin, 2005a) geographies that alter the nature of governmentality and access.

\footnotetext{
${ }^{1}$ Jensen (cited in Becker, 1952) details that capta are units of data that have been selected and harvested from the sum of all potential data. Here, data (derived from the Latin dare, meaning 'to give') is the total sum of facts that an entity can potentially 'give' to government or business or whomever is constructing a database. Capta (derived from the Latin $\mathrm{ca}$ pere, meaning 'to take') are those facts that those constructing the database decide to 'take' given that they cannot record or store everything (also Dodge and Kitchin, 2005b).
} 
As Foucault $(1976,1978)$ has documented, particularly in his genealogies, modern life is infused with the apparatus and systems of governmentality that seek to order and regulate the behaviour of individuals by producing a particular form of rationality designed to ensure good government through a more efficient and rationalized legal and social field (McNay, 1994). These systems hold power because they instil a regime of self-disciplining and conformity through the threat of discipline for non-compliance with social norms and rules. The systems intervene in all aspects of daily life and are supported by technologies designed to monitor and evaluate behaviour, and that this surveillance is potentially ever-present. Such technologies include censuses, health records, school attendance registers, criminal records, tax records, registration of births, deaths, marriages, and more recently CCTV footage, mobile phone records, and as we document various systems surrounding automobilities and its infrastructures.

As many commentators have noted with respect to governmentality and automobilities, the long held myth of the 'freedom of the road' has never been a reality, with driving being subject to various forms of state regulation that have sought to self-discipline drivers through the threat of direct disciplining (official warnings from traffic police, fines, disqualification, confiscation of vehicles, imprisonment, and so on). The first cars required a person to run in front of the vehicle waving a red flag to warn unsuspecting pedestrians. Not long after roads became managed in order to make them more serviceable and navigable for drivers. This included the introduction of road grading schemes and then consistent number identification, the application of standard road markings and signage, and the introduction of traffic lights and speed limits to regulate flow. These regulations became fixed in material-legal form as the Highway Code, introduced in Britain in the 1930s and now common in most countries (Featherstone, 2004). Highway codes were complemented by the formalised testing and licensing of drivers by the state. In Britain this became a legal requirement with the passing of the 1903 Motor Car Act (Higgs, 2001). In the same Act, the registration of vehicles was introduced, mandating the visual display of a license plate that uniquely identified each vehicle and enabled the police to trace the owner's address details in local registries. Later in the twentieth century, drivers were required to insure vehicles they owned, limit their consumption of alcohol, wear seat belts and not use a handheld phone when driving ${ }^{2}$ and automobiles became subject to a raft of other forms of regulation including pollution orders, safety and fuel efficiency standards, and regular road wor-

\footnotetext{
${ }^{2}$ In Britain, the legal limit for alcohol was set in the 1967 Road Safety Act, www.homeoffice.gov.uk/rds/pdfs04/r258.pdf, the mandatory wearing of seat belts came into effect in 1983 after a lengthy campaign by road safety activists, www.rospa.com/history/beltingup.htm and the use of handheld mobile phones whilst driving was banned by regulation in December 2003, www.thinkroadsafety.gov.uk/advice/mobilephones.htm.
}

thiness testing, and marked with globally unique VIN codes. ${ }^{3}$

As this short list demonstrates, with the transition from novel sight to ubiquity, drivers and vehicles have been increasingly drawn into the orbit of governmentality through successive layers of monitoring, identification, and regulation by the state. The objective of this paper is to understand how software is changing the governmentality of driving and, secondly, how this governmentality alters the spaces of automobile driving. Our analysis sets out what we believe is the start of a significant shift in the operational nature of this governmentality, namely a move from systems of regulation that work principally through the oligoptical surveillance and self-disciplining of drivers, to automated systems of management using software that seek on the one hand to make (self)disciplining more panoptic, and on the other use new code-based processes of information capture that reshapes (rather than disciplines) behaviour. As we illustrate through our examples, key to this shift has been the introduction of software-enabled and distributed technologies that mediate in various ways road infrastructure, vehicles, and drivers. These new technologies build on, but significantly extend and intensify, earlier computer-based administrative systems introduced since the late 1960s, such as those developed in Britain by the Driver and Vehicle Licensing Centre for the centralised licensing of drivers, and registering and taxing vehicles (Higgs, 2001). Significantly, we would argue, they enable the automatic production of space - that is they bring particular spaces, at particular times, into being in novel ways through their execution (see Thrift and French, 2002; Dodge and Kitchin, 2004, 2005b).

In order to structure our discussion, we have divided the paper into three sections. In Section 1, we document some of the important ways in which new computerised technologies and software systems are being applied to automobilities (the assemblage of interests concerning road usage drivers, vehicles, manufacturers, taxation and registration institutions, etc.). Next, we explain the significance of these technologies, outlining a theory of automated management. Using this theory, in Section 3 we examine how these technologies automatically produce space with respect to access, movement and flow. We also detail gaps in their application due to unevenness in implementation and forms of resistance.

\section{The changing landscape of automobilities}

The social, material and monetary 'footprint' of the automobility assemblage is vast. In Britain alone, the visible infrastructures comprise 31.4 million licensed road vehicles,

\footnotetext{
${ }^{3}$ The VIN (vehicle identification number) is a 17 digit code, stamped physically into the chassis of all vehicles, that specifies the marker, the place and year of manufacture, the model and an individual serial number. It was adopted as a global identification code in 1978 as ISO 3779 standard. It is designed primarily to deter theft and prevent fraud.
} 
traversing $387,674 \mathrm{~km}$ of paved road (DfT, 2005), and being re-fuelled at 11,400 petrol stations (HoC, 2004). In 2004 some 498.6 billion vehicles kilometres were driven, 3221 people were killed and a further 31,130 seriously injured (DfT, 2005). Huge expanses of lived spaces are occupied with the storage of vehicles (Jakle and Sculle, 2004), and other externalities of automobility, such as vehicle noise and pollution, seriously plight many areas. Automobility is also a huge revenue generator for private industry and for governments. For example, the British Treasury raised some $£ 22.6$ billion from fuel duty and a further $£ 4.9$ billion from Vehicle Excise Duty in 2003/2004 (DfT, 2005). Keeping this complex assemblage operational increasingly depends on the use of software systems. As detailed below, road infrastructures are controlled by sophisticated management systems, vehicles are ever-more reliant on 'black boxes' that monitor and control driving performance, and information systems are used in administration, generating huge databases of events and detailed profiles of drivers. The three subsections that follow provide examples of these new technologies with respect to infrastructure, vehicles and drivers.

\subsection{Road infrastructure}

Traditional road infrastructure of tarmac, conventional signs, and traffic management in the form of pre-set traffic lights and fixed tolls, are rapidly becoming complemented with 'smart media' - digital, networked infrastructures controlled by software - that aim to monitor and regulate the road system in real-time. Such digital infrastructures relate to traffic management such as the automatic altering of traffic light sequences and updating of road speed signs, automatic logging of vehicular congestion and variable toll charges, and the networking of speed, red light, bus-lane cameras designed to discipline driver behaviour (from not driving too fast, not jumping red lights, and not occupying bus lanes). These software-enabled technologies, when used in combination, aim to produce wide area intelligent transport systems that make more efficient use of roads. Transport for London is developing one such system to manage the city's traffic (TfL, 2003). At present, they use a system called dashboard which collects and analyses over 300 road network performance indicators. ${ }^{4}$ In addition, London Traffic Control Centre uses a network of 75 cameras to monitor and co-ordinate traffic flow at key strategic locations $^{5}$ (this system also feeds the media with congestion reports and is used to update an information website). Traffic light sequencing at some 2400 junctions and pedestrian crossings are controlled using a comprehensive, traffic management system (called SCOOT, split cycle offset optimisation technique) which optimises to real-time demand

\footnotetext{
${ }^{4}$ Traffic Management, November 2003 www.transportforlondon.gov.uk/streets/dtm/pdf/getting-london-moving.pdf.

${ }^{5}$ Capital Cams, Transport for London, October 2005, www.tfl.gov.uk/ $\mathrm{tfl} /$ capitalcams/index.shtml.
}

measured by vehicle sensors (under-road induction loops, microwave and infrared detectors) (TfL, 2003). In addition, several thousand other traffic lights in London are centrally monitored by fault-detection software. Traffic flows are also monitored at a larger scale, with networks of passive sensors installed on trunk roads and motorways; in Britain the largest operator of such systems is TrafficMaster which is a commercial enterprise selling real-time traffic data derived from some 7500 detectors. ${ }^{6}$ Strategic routes in the network also have variable message signs, set remotely by control centres, to give drivers warning messages.

Furthermore, information from these systems are used to coordinate traffic responses and to provide data for strategic planning through traffic simulations and constructing statistical models of the road system; road maintenance and upgrading is also planned using GIS-based applications. In addition, transponder recognition units have been fitted to car-parks, garages, toll booths, and so on, to allow vehicles carrying an appropriate transponder to pass automatically through (and record or deduct any necessary charges) and also along bus routes and to the front of buses to enable the real-time updating of bus arrival times at bus stops (TfL, 2003).

In the case of a number of British cities, camera networks increasingly use automatic number plate recognition (ANPR) systems to pattern match license plate numbers with owners. As well as being used to automatically bill those that contravene traffic law (e.g., speeding drivers), ANPR also underpins other forms of regulation such as the congestion charge payment system that was introduced in London in February 2003, primarily to try and reduce traffic congestion within $21 \mathrm{~km}^{2}$ of central London, although the system is now also used to combat potential terrorist attacks and cameras record outside of congestion billing times (Coaffee, 2004). This system consists of 688 networked cameras at 203 sites $^{7}$ and uses ANPR surveillance to ensure payment. It seems likely that ANPR will be more widely deployed in Britain for active policing and also for routine monitoring of motor tax evasion (ACPO, 2005) and at petrol stations to combat people driving off without paying (Oliver, 2004). Other related technologies are being used for anti-terrorist purposes. For example, the US Department of Homeland Security plans to begin issuing special identification devices to foreign visitors arriving by foot and by car by July 31, 2005 (Gilbert, 2005). The devices will contain an RFID (radio frequency identification) chip that uniquely identifies the visitor. Border officials will be able to scan the chips from a distance, with the visitor id-code broadcast via radio signal. In Britain research into electronic vehicle identification (EVI) has also been undertaken and it has been

\footnotetext{
${ }^{6}$ TrafficMaster, UK Network, October 2005, www.trafficmaster.co.uk/ page.cfm?key $=$ network

7 Details from Congestion Charging fact sheets: camera enforcement, Transport for London, undated, www.tfl.gov.uk/tfl/cclondon/cc_fact_sheet_ enforcement.shtml.
} 


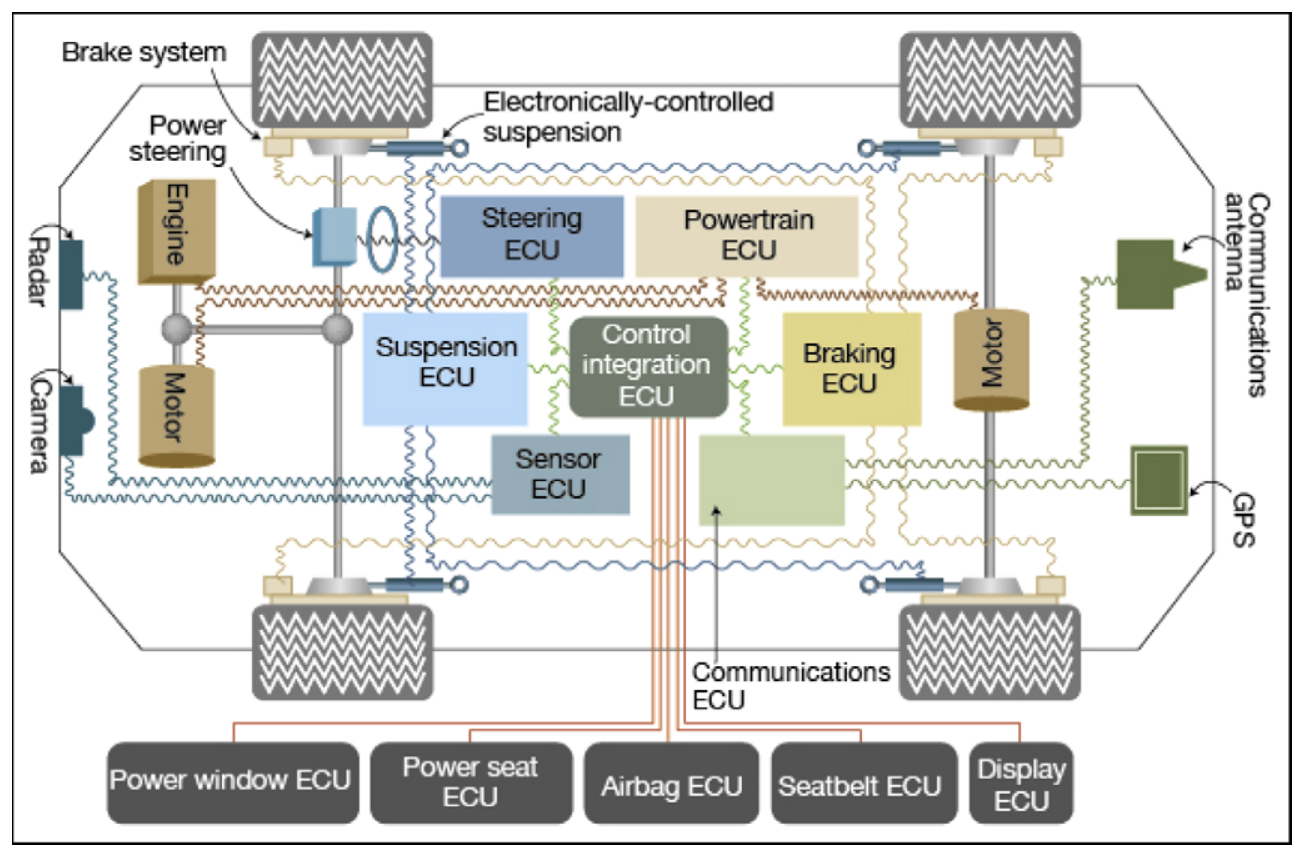

Fig. 1. The majority of new cars contain multiple electronic control units (ECUs) which, singly and in combination, manage many aspects of automobile mechanics and performance. (Source: adapted from Kariatsumari, 2005, p. 30.)

reported that the government is considering a so-called 'eplates' system using RFID tags to facilitate the automatic identification of cars and to combat fraud with fake number plates (Baard, 2005).

The development of wide area intelligent transportation systems are not limited to the state and a number business interests are seeking to develop commercial prototypes. For example, Ford, in partnership with a number of city and state transportation departments in the US, are presently constructing such a system whereby cars and the highway communicate with each other to guide drivers around traffic jams and through bad weather. ${ }^{8}$ State and emergency vehicles will generate data with respect to other traffic (vehicle speed, location and heading) and weather (wiper operation, lights on/off, outside temperature, traction control) and transmit this information to a central control. Analysis of the generated data is then communicated to other drivers via highway message signs, 511 (informational) telephone services, and related websites, and used to deploy road and maintenance crews.

Another important aspect of road regulation is that of parking. Given the pressures upon urban area for mobility, parking needs to be regulated to help manage the road infrastructure and also to provide an income stream for its maintenance. In order to help with the regulation of socalled 'smart-parking' systems are being bought to bare on the issue. These systems aim to make the regulation more efficient, more convenient, and reduce payment evasion. Several different prototypes are being developed including 'smart meters' able determine when parking bays are in use,

\footnotetext{
${ }^{8}$ Ford studies "intelligent" cars and highways, February 27, 2004, www.canadiandriver.com/news/040227-3.htm.
}

specialised PDAs for parking attendants, and infrared license plate scanners for rapid 'drive-by' monitoring of street parking.

\subsection{Vehicles}

"It is not just the driver who possesses intelligence and has intentionality and capacity to act, the governance of the car is increasingly delegated to the machinic complex of the car which is able to sense its environment, make judgements and act accordingly." (Featherstone, 2004, p. 10)

Since the early-1990s, new vehicles have been conceived primarily within silicon and software. Their design and engineering testing has been undertaken within CAD systems, and the vehicles manufactured in plants of computerised robotic production lines, supplied through global supply chains that are enabled by networked information systems. Increasingly, software is becoming bound into the very materiality of the vehicles themselves, with the calculative power of code supplanting the cognitive ability of the human. As ?Thrift (2004, p. 50) notes, "[a]lmost every element of the modern automobile is either shadowed by software or software has become... the pivotal component." Contemporary cars (especially luxury models, but filtering down as the costs falls) are a collection of computers on wheels (Fig. 1). Indeed, they represent one of the densest concentrations of digital computing and embedded software that most people encounter in the everyday environment.

While cars still appear the same and drive in the same fashion, the onboard systems are increasingly aware of their capacity through diagnostic sensors that measure 
their performance, can plot the vehicle's location through GPS-tracking, and monitors the actions of the driver (their use of gears, how they accelerate and brake, and so on). This information is most visibly communicated to the driver through the replacement of mechanical instruments on the dashboard with digital displays. However, most software operates in hidden ECUs (electronic control units effectively black boxes) (see Fig. 1). It has been estimated that the average car has 30-40 such ECUs containing perhaps as much as 35 million lines of code (Duvall, 2005). These black boxes can potentially log and store information for future use by the driver or manufacturer ${ }^{9}$ (to evaluate warranty claims; see Austen, 2003), others are real-time 'driver assistance' systems (see next section).

In addition, whereas until recently, the car had been a self-contained unit, the inviolate nature of vehicle space is increasingly being punctured by automatic communications. Here, information generated by on-board ECUs can broadcast to third parties via telematic monitoring networks. It is estimated by the Telematics Research Group that over a third of all new vehicles produced by 2006 will have telematic systems as standard (Bunszel, 2002). One such system is the OnStar Advisor system in General Motors cars in the US. The Advanced Automatic Crash Notification element contacts OnStar service on detection of a crash, and figures report that some 700 airbag notification per month were being received in early 2004 (PRNewswire, 2004). A range of other driver initiated requests were also reported, including 500 stolen vehicle location requests, 20,000 requests for roadside assistance, 36,000 remote door-unlock requests and 19,000 GM Goodwrench remote diagnostics requests. A major automotive initiative led by the European Commissions on eSafety ${ }^{10}$ is seeking a similar pan-European emergency assistance system installed as an option in all vehicles by 2009 .

In other cases, GPS-based navigation and radio tracking systems can be used to monitor the real-time location of a vehicle to the nearest few metres. Some car rental companies are now using such systems to monitor where rental drivers take the vehicle, with penalties imposed if the car is taken to somewhere outside of the rental contract (e.g., out of state or off-road; Elliot, 2004). A number of insurance companies are planning on introducing similar devices to calculate variable insurance premiums that reflect driver behaviour and the locations they leave their vehicles (see next section). Other systems are sold as products to parents so as to monitor the location of teen drivers. For example, Omnitrack, designed as an anti-theft device, allows parents to track in real-time where a child's car is and how fast they are travelling. ${ }^{11}$ It can also be programmed so that the com-

\footnotetext{
${ }^{9}$ As a consequence, vehicles are increasingly exhibiting unexpected, and hard to diagnose, failures due to software 'glitches'. Just as users have become accustomed to software upgrades and continuous security patches on their PC, so drivers will require the same to keep their car moving.

${ }_{10}$ Details available at www.escope.info.

11 Details available at www.omnitrack.net.
}

pany will contact the parents if any set parameters (e.g., speed or distance) are exceeded. A range of distanciated driver management systems, similarly using GPS-tracking, are also becoming more common across commercial vehicle fleets. These monitor the behaviour of drivers operating commercial delivery vehicles, taxis and buses, and supplement electromechanical tachographs that regulate drivers hours. Vehicles can also generate data with respect to other vehicles and the surrounding environment. For example, 1000 buses in London carry cameras directed at the road. ${ }^{12}$ These record video footage along with time, date, location (determined by transponders along the route), route number, bus ID, with the footage used to discipline drivers driving or parked in bus lanes.

\subsection{Drivers}

To be a legal and legitimate car driver in developed countries means enrolling in a raft of interlocking information systems of authorisation and ongoing validation. In many respects, the 'right' to own and drive a car are subject to (attempted) complete control by the state to an extent that is unprecedented in relation to almost all other mass consumer activities. In Britain, and common in most OECD countries, drivers are fixed within a five point control-grid: a valid license, insurance cover, registration of the vehicle, road taxation, and an annual vehicle roadworthiness test. Penalties are applied for failure to meet, on a continuous basis, any one of these requirements. Despite this level of control, in many countries there is a ingrained cultural expectation that passing the driving test and obtaining a license is an essential part of the rights of passage to adulthood. In Britain 32.2 million people, some $70 \%$ of the adult population, hold a driver's license (DfT, 2005). Indeed, the driving license as both a material token of identification that can be displayed on request and as a verifiable record in a governmental database has become one of the most valuable 'codes of life' (Dodge and Kitchin, 2005a). Software automation, however, is increasingly altering the nature of the driving license in two respects. First, information about a driver, such as legal infractions (parking fines, speeding fines, penalty points) or medical conditions that preclude driving can be easily stored to create a dynamic profiling tool. Second, this information can be used as a means to regulate drivers and identify lawbreakers. With the introduction of technologies such as $2 \mathrm{~d}$ barcodes, RFID tags and biometric identifiers, fraud with respect to false licenses will become more difficult.

Beside government registration and licensing, drivers are also ineluctably held within the orbit of various private sector information systems in relation to the purchasing, servicing and, particularly, insuring their vehicles. The legal requirement to purchase insurance cover means that drivers

\footnotetext{
12 Mayor's Transport Strategy: Buses, October 2005, www.london.gov.uk/ mayor/transport/buses.jsp.
} 


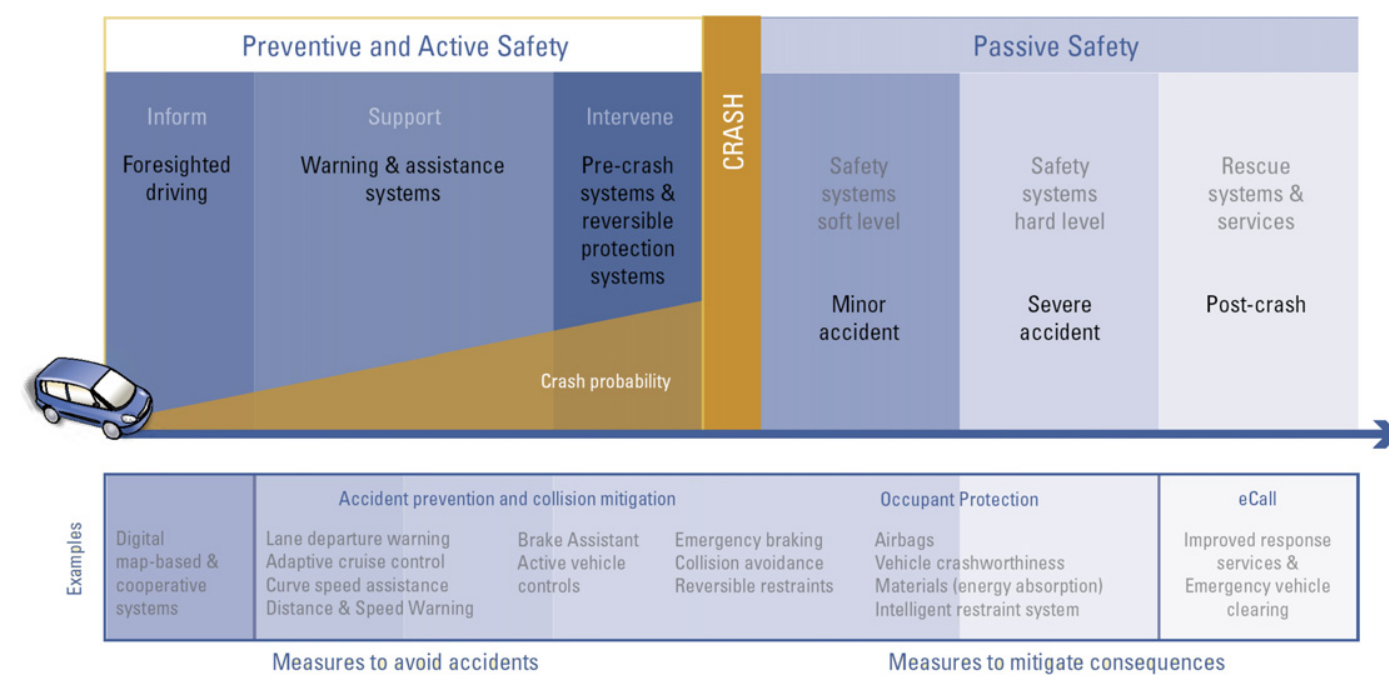

Fig. 2. eSafety system and technologies concept diagram. (Source: eSafety project flier, 2005, p. 10, www.escope.info/index.html?file $=312$.)

are subject to intensive 'software-sorting' (Graham, 2005), that is a profiling and ranking scheme used to automatically make decisions on an individual's potential risk, entitlements, services, and the rate to be charged and thus socially differentiates and classifies potential customers to the benefit of the insurance company. Intense competition in insurance provision, especially to capture the most profitable segments of the market, means that risk models are becoming ever more sophisticated drawing in a wider range of socio-economic and lifestyle indicators. Consequently, more and more personal data is being held by insurers and is being actively data-minded to identify actionable patterns and new trends. As discussed below, this is has the effect of regulating driver participation through differential financial barriers.

Perhaps more worryingly for some, software-enabled technologies seem likely to radically alter the financial regime of driving in the near future. With respect to insurance it is anticipated that there will be a structural shift from a fixed annual premium based largely on personal circumstances and vehicle type that is paid in advance to variable premiums dynamically calculated (logically on a daily basis) by driving patterns (kilometres driven, driving route, location of parking, time of day of journeys, and so on) and perhaps even driving behaviour (speeding, evenness and harsh braking, jumping red lights, etc.). Such journey-byjourney risk calculation will be facilitated by telematics networks working as a potent socio-technical fix capable of continuously tracking vehicles (as discussed above). Parallel to this is a possible shift in government taxation systems from fixed to dynamic ones based on road pricing ${ }^{13}$; that is, road users will be charged per distance travelled not a fixed fee. All proposed road pricing schemes are heavily depen-

\footnotetext{
${ }^{13}$ For example in Britain, see Government Response to the Select Committee Report, Road Pricing: The Next Steps, CM 6560, 20 July 2005, www.dft.gov.uk/stellent/groups/dft_roads/documents/divisionhomepage/ 032120.hcsp.
}

dent digital technologies to track vehicles continuously and software to analyse movements to determine charging levels (see for example, DfT, 2004a).

In addition to external systems of governmentality, drivers are subject to internal systems of software-enabled regulation through driver assistance systems embedded entirely in the vehicle itself. These systems consist of two broad classes: those aimed at increasing driver safety and those aimed at enhancing convenience. Both these aims can be achieved at a conceptual level by using software to (i) reduce the cognitive burden on drivers (e.g., turn-by-turn voice navigation instructions), (ii) reduce the level of kinaesthetic and spatioperceptive skills required (e.g., distance detection within parking aids), (iii) reduce the physical strength/endurance needed to drive (e.g., active steering, active cruise control), and (iv) sense environmental conditions beyond normal human senses (e.g., black ice detector).

With respect to 'safety through software', the assumption is that drivers are often the 'problem' and need to be protected from themselves. Fig. 2 conceptualises the range of 'intelligent vehicle safety systems' focused on preventing and then responding to the ultimate driver 'error' (a crash event). Prior to a potential crash, a number of softwareenabled systems are available (or likely to become available) to inform the driver, and then support the driver, through active warning messages concerning what the software determines to be dangerous behaviour/environments (e.g., lane departure warning that detects the wheels crossing road markings). Closer to the crash event itself, software systems do not simply warn the driver, they actively engage to mitigate as far as possible a crash (e.g., active braking). Once the crash has occurred further systems react to minimise driver injuries (e.g., intelligent airbag deployment), and automatically summon emergency services. In other words, a radical change in the way a vehicle's controls work is taking place, with a shift away from direct physical connection between the driver's embodied actions and mechanical response to software-mediated 'drive-by-wire' 
operations. In the case of 'smart' brakes, for example, a foot pressing down on the pedal does not operate hydraulically the brake itself, but rather sends a signal to an ECU, which determines the level of braking required algorithmically and in turn send out a signal to instruct the brake mechanism to operate. In contrast, many convenience technologies in luxury cars use software to try to remove aspects of 'drudgery' from driving. For example, keyless entry uses proximity radio signals to detect the body's arrival at the door; so-called 'memory seats' are able to automatically restore the particular settings for individual drivers; automatic wipers detect rain on the windscreen.

\section{New forms of automobility governmentality}

Our thesis is that these various forms of softwareenabled technologies are important because they are recasting the nature of governmentality with respect to automobilities. In short, our contention is that these systems represent the beginnings of a new mode of regulation - which we term automated management - that differs in several, fundamental ways from established forms of governmentality. The principal difference software makes being that of automation, which we define as the ongoing production of a process without the mediation of a person. In relation to automobilities, there are two distinct automated processes at work. First, existing manual or electromechanical systems aimed at regulating automobilities are being supervised by computer systems that automatically manage all aspects of the system. Second, computer systems are introducing wholly new forms of automated management, rather than augmenting older systems.

With respect to the first form of automation, traditional forms of surveillance such as radar traps and speed camera systems are being made more effective through the automatic monitoring of a system and the application of penalties by algorithmic processing. Until relatively recently the recording of driver (mis)behaviour was limited, relying principally on the vision of police officers who were thinly scattered across the road network. Traffic police enforced a traditional surveillance model in that drivers were not aware of where officers might be, so were encouraged to discipline their driving in case they encountered one. The first speed cameras started the process of automation, but the collection and processing of film, and the use of dummy boxes was only a partial improvement. New digital, networked cameras using ANPR provide a much more rigorous system of near real-time surveillance. Such developments are designed to instil a stronger regime of self-discipline, the main premise being that if people know they are being monitored more effectively they will drive more safely, reduce fuel consumption, maintenance and insurance costs, and refrain from illegal activities such as car theft. ${ }^{14}$

\footnotetext{
${ }^{14}$ Although opponents of speed cameras argue that what they do is temporarily reshape driver behaviour, making them slow only in the immediate gaze of the camera.
}

In contrast to this automated version of existing systems of governmentality through surveillance, a new form of automated management has emerged in recent years, that of capture. The capture model, as first conceived by Agre (1994), acknowledges that the mechanisms by which information is being gathered is increasingly an integral part of the same system that they seek to monitor and regulate, for example a computerised till in a shop that logs its own use by the checkout worker by automatically collecting information about worker output by monitoring scan rate and that these mechanisms in turn redefine and reconfigure that system (e.g., change workplace practices, in this case how the job of a till operator is undertaken by moving items across a laser scanner), quite often in real-time. In other words, rather than an external surveillance system working to self-discipline, capture is an wholly internalised feature of an activity and actively seeks reshapes that activity. Capture is still a form of surveillance but one that it is not an addition to the system to make it more efficient; it is an inherent part of the system. As such, the capture model differs in several respects to more traditional forms of surveillance-based, self-disciplining forms of governmentality (see Table 1; Agre, 1994; Kitchin and Dodge, 2006).

The capture model works to discipline not self-discipline, the mode of capture seeks to be exhaustive rather than threatening exhaustivity exerting direct regulation over what the driver can and cannot do. For example, cars are now being designed in such a way that activities which external systems sought to self-discipline (by fear of being caught by the police) are reshaped by the car itself - such as the code in the vehicle's ECU will not start the engine unless it senses that the driver's seat belt is clicked in place. Moreover, like automated surveillance capture is fully automatic in nature rather than operated by people, it is increasingly distributed, mobile and operates in real-time rather than being static. Of note, is that unlike other contexts such as air travel or workplaces, capture systems are as yet less obvious and less prevalent and often work to reshape driving experience, but not necessarily the driver's praxis. Indeed, automated surveillance and capture systems often work closely together, with the capture elements working in the background. For example, within many surveillance systems capture models are at work redefining how drivers are assessed and processed and automatically disciplined or rewarded. The effect of this hybridisation of automated surveillance and capture systems is to make automobilities into an increasingly legible landscape "simple and visible forms of order" (Curry et al., 2004, p. 359).

Importantly, systems of automated management are employed by diverse interests. On the one hand, state agencies are a significant driver of new technologies, pushing their development for reasons of efficiency and congestion reduction (improved traffic management), safety, law enforcement, security (from terrorist threat), revenue recovery and anti-fraud (catching untaxed cars and unlicensed drivers). On the other hand, are business interests such as 
Table 1

Contrasting surveillance and capture models of governmentality

\begin{tabular}{|c|c|c|}
\hline Parameters & Surveillance model & Capture model \\
\hline Metaphor & Vision & Linguistic \\
\hline Site & Collection of information external to a system & Capture of information inherent to a system \\
\hline Extent & Selective, but threatens exhaustive & Exhaustive (within its frame of reference) \\
\hline Mechanism & Disciplines through self-disciplining & $\begin{array}{l}\text { Manages by modulating experience and disciplining } \\
\text { activity (sometimes in way unknown to the person) }\end{array}$ \\
\hline Visibility & Always visible & Often hidden, sometimes deliberately secret \\
\hline Capta & Collected information is representation & Captured information is representation and product \\
\hline Agency & $\begin{array}{l}\text { People operated (e.g., somebody watches the } \\
\text { camera or reads the file) }\end{array}$ & Software operated (e.g., automated) \\
\hline Viewfield & Static (at fixed points with fixed views) & Typically distributed and increasingly mobile \\
\hline Temporality & Partially dynamic, usually used retrospectively & Dynamic - updates and potentially regulates in real-time \\
\hline Organization & Centrally organized and structured (statist) & Diverse, locally organized, institutionally structured (network) \\
\hline Predictability & Non-predictive & Sometimes predictive, facilitates simulation \\
\hline
\end{tabular}

Source: Adapted from Kitchin and Dodge (2006).

car manufacturers, insurers, rental car companies, garages and mechanics, and other third parties such as transport planners and road safety campaigners argue that such technologies provide value-added services, reliable journeys, cost-effectiveness, enhanced driver experience, risk reduction and so on.

\section{Automatic production of driving space}

Cars "exert an awesome spatial and temporal dominance over surrounding environments, transforming what can be seen, heard, smelt and even tasted." (Sheller and Urry, 2000, p. 746)

One of the main effects of governance through systems of automated management is that they create new socio-spatial arrangements - they automatically produce space by actively shaping road environments, vehicle capability, performance and handling, and driver knowledge, experience and behaviour (either inherently as capture or through external surveillance). Here, we conceive of space in ontogenetic terms wherein space is seen to be constantly bought into being through practices of people in combination with software (Dodge and Kitchin, 2005b). That is, space is endlessly recreated in the moment; it is "a continuous process of matter and meaning taking form as divergent realities technical and non-technical, human and non-human, living and non-living - constantly come into contact to create new conditions" (Dodge and Kitchin, 2005b, p. 178). Importantly, new software-enabled technologies make a difference because they alternatively modulate the form, function and meaning of space - they produce driving spaces in new ways - albeit in a manner that is layered upon existing spaces, and produce new driving subjects (by transforming the socio-spatial conditions of driving).

In many ways the spaces being bought into being do not look very different to non-software mediated driving spaces, but we would argue that their production is different in a myriad of ways that have countless small and large effects. These effects are scalar, producing alternative spaces from the micro-setting of the engine components and car systems, through into the vehicle interior, road infrastructure, and wider automobility assemblage including petrol stations, oil refineries, manufacturing plants, taxation agencies and insurance companies, and so on. So for example as detailed earlier, the interior of the car is alternatively modulated by new systems that seek to enhance the driving experience such as a satellite navigation system giving turn-byturn instructions. Road infrastructure is augmented by additional architecture such as induction loops, toll booths, traffic lights controlled by adaptive management systems, or is redesigned into new layouts, or is subject to variable road restrictions such as variable speed limits, all aimed at demassifying and regulating flows (see Fig. 3). Further new spaces have been created such as specialised control rooms and 'server farms', and other spaces of calculation such as insurance and taxation back offices have been reconfigured through the use of distributed intranets. The role of automated management in these new productions is not simply one of regulation, but is also a normative one enabling and providing helpful capacity to drivers, vehicles and the road network itself. These new spaces are produced, we hypothesise, in at least three ways, affecting access, movement, and flow.

\subsection{Access}

"The gates and barriers that contain, channel, and sort populations and persons have become virtual." (Lyon, 2003, p. 13)

One of the principal tasks of many of the new softwareenabled technologies is to regulate the access of vehicles to certain spaces. In other words, they constitute what Graham (2005) refers to as 'software-sorted geographies'. Such geographies include those enabled through capture-based systems embedded within the driving-scape including automated speed, bus-lane, and red light surveillance cameras (using ANPR software), and radar-activated speed warning signs, toll roads ('easy-pass' tags), garages (door-opening 

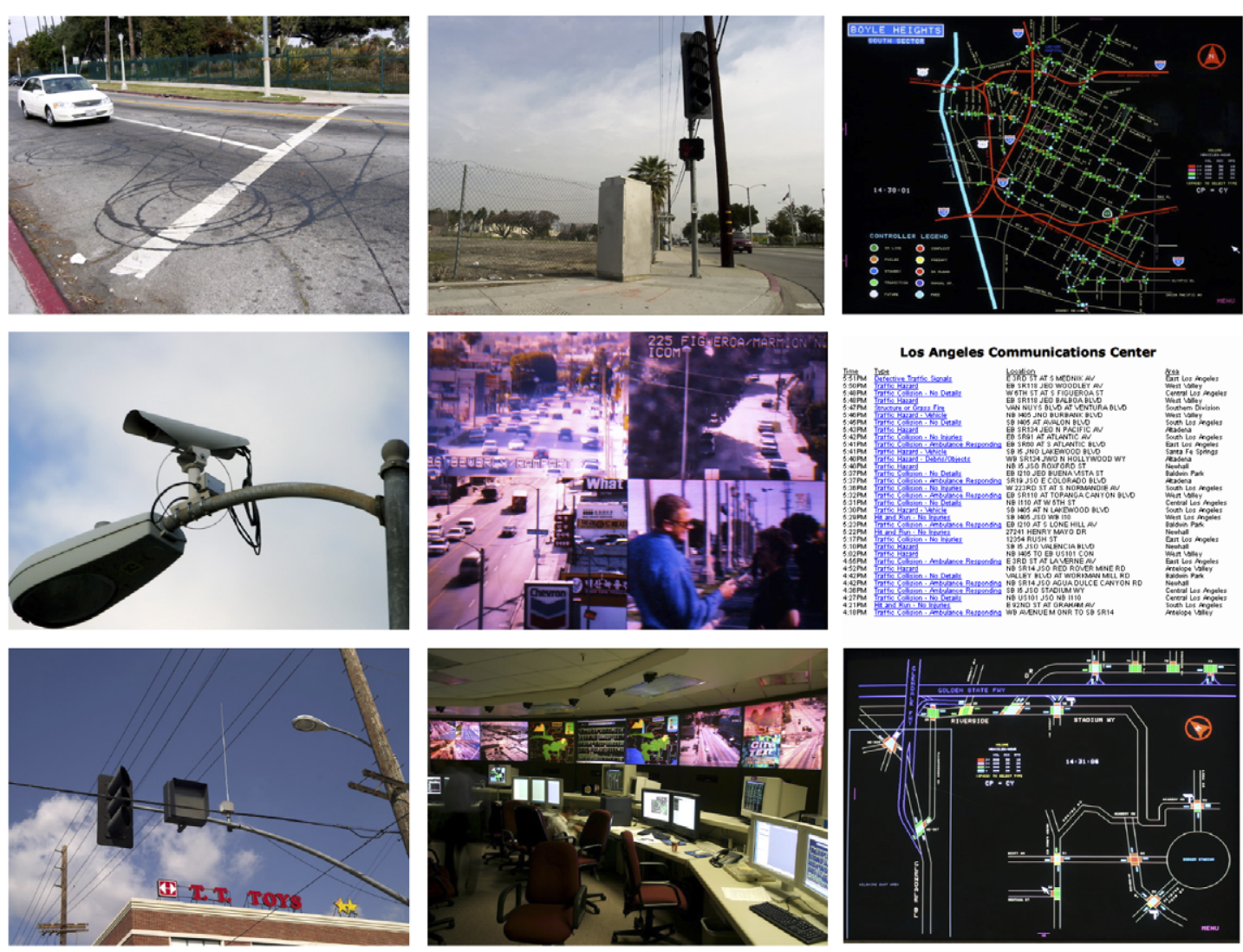

Fig. 3. A montage of images of software-driven technologies that automatically manage the road infrastructure in Los Angeles. (Source: Loop Feedback Loop: The Big Picture of Traffic Control In Los Angeles Exhibition, 2004. The Center for Land Use Interpretation, www.clui.org/clui_4_1/ondisplay/loop/.)

transponders), car-parks (swipe cards and smart meters), and those that seek to regulate access to the system as a whole such as government agency systems that keep track of capta on driver licenses (and any penalties) and vehicle tax payments, and in insurance systems that note whether a driver has insurance cover and calculates rates on the basis of risk. In both cases, software-enabled technologies ensure differential access on basis of certain criteria, usually identity or ability/willingness to pay, and thus ensure that the road infrastructure is appropriately segmented; those who are entitled have access to the right parts of the system and those who do not are excluded. In many respects, the improved capability offered to 'police' the roads to exclude the uninsured, unlicensed and disqualified drivers is sensible with respect to road safety. Such drivers are deemed to be disproportionate accident risk (see DfT, 2004b, for data on the UK). The systems are sold on the basis of making driving more secure, safe and law-abiding.

Of concern to some commentators, however, is that financially based, software-driven 'social sorting', works to benefit well-off drivers while disproportionately penalising the poor and those classified as higher risk based on the neighbourhood in which they live (see also Lyon, 2003), either by denying them access to a section of road or area, forcing them to take more expensive and less convenient routes in terms of time and distance, pushing them into using less flexible public transportation modes or by having to pay higher premiums ('discrimination-by-postcode' where poorer areas tend to have high premiums due to higher crime rates). Such sorting thus works to further marginalise and exclude poorer sections of society from essential infrastructure.

\subsection{Movement}

A specific set of software-enabled technologies focus on precisely locating vehicles and tracking their movements through the road infrastructure. These systems' use capta from GPS and telematic networks to monitor in real-time a vehicle's location in space-time and other ancillary capta such as speed and direction of travel. Generally the systems serve two purposes. On the one hand they perform as personal navigation aids augmenting the driver's knowledge to find the fastest, shortest, or most efficient route between locations; ultimately it should be impossible for drivers to get lost. ${ }^{15}$ On one level this improvement in efficiency is productive, helping to save drivers' time and achieving greater degree of sustainability in automobility by reducing wasted miles driven. On the other, they are disciplining devices used by concerned parties (rental companies, employers, parents,

\footnotetext{
15 The Hertz car rental company in United States markets it GPS-based navigation as the 'NeverLost' system, http://hertzneverlost.com.
} 
police) to generate continuous tracks of telematic capta revealing the position of vehicle and potentially the driving habits of the driver. In both cases they influence how space is bought into being by changing how planning/tracking movement is performed (Dodge and Kitchin, 2005b).

The nature of movement is also monitored internally by management systems of the vehicle that record the driver's actions in terms of speed, gear use, etc. They are designed to discipline, often without knowledge, how people drive around the road system to increase safety and enjoyment, although they are largely invisible to the driver. These systems are increasingly being used by car manufacturers to evaluate warranty claims and insurers to verify liability (cf. Austen, 2003).

Furthermore, there are significant ancillary socio-spatial impacts in terms of privacy because driving is becoming a much less anonymous activity. Clearly, this is part of a long ongoing process, including the mandatory displaying of license plates on all vehicles and the deployment tachographs (so-called 'spy in the cab') in lorries and coaches to enforce professional drivers' working hours. However, the software algorithms in movement monitoring system are much more invasive and likely to be widely implemented and mandatory through schemes such as road pricing and pay-as-you-drive insurance that will generate detailed and continuous capta streams. As such, these schemes are threatening to make the "disappearance of disappearance" (Haggerty and Ericson, 2000, p. 619) absolute within the automobility assemblage.

\subsection{Flow}

Traffic management systems, rather than concentrating on specific vehicles, seek to monitor and regulate the traffic system as a whole and, in particular, the efficient flow of vehicles. As noted above, such systems now consist of a highly complex assemblage of networked infrastructure (e.g., vehicle sensors, traffic lights, variable warning signs, and so on) and sophisticated software programs to manage them. Depending on the capta of traffic levels, weather conditions, road works and so on the parameters and algorithms in traffic management systems actively, and automatically, reshape the system by controlling in realtime how vehicles can negotiate the road network.

The algorithmic rules within traffic management systems are also beginning to be able to automatically demassify flows, to apply differential rules for different classes of road user. Co-ordinated control by the SCOOT software used in central London and other British cities, for example, allows traffic light phasing to be changed dynamically to prioritise access for buses at busy junctions as well as providing a socalled 'green-wave' facility for emergency vehicles. ${ }^{16}$ As well as easing flow, certain actions are specifically being targeted

\footnotetext{
16 The "SCOOT" urban traffic control system, undated. www.dft.gov.uk/ stellent/groups/dft_roads/documents/pdf/dft_roads_pdf_504797.pdf.
}

to block the flow of other classes, particularly those breaking the law and of interest to the police. For example, in Britain, the police's push for national ANPR monitoring capacity has been proselytised as "deny criminals the use of the roads" (ACPO, 2005) by making the risk of being caught driving illegally into a certainty. There are clearly many issues here regarding privacy and confidentiality (see Bennett et al., 2003; Dodge and Kitchin, 2005a).

\subsection{Gaps in automated management}

Despite the shift towards a mode of automated management it is clear that there are still significant gaps in its application that mean that it can be resisted, subverted, and avoided. Consequently, the automatic production of driving space is uneven and experienced unequally. At a basic level, there is a marked variation in the implementation of automated technologies within automobility infrastructures. At the macro-scale, there are large variation between countries and cities depending on government policy, institution will and spending regimes. For example, Britain has embraced to much greater degree the rolling out of such infrastructure than say Ireland. And within Britain, London has had a disproportionate investment in such systems compared to other cities. In part this is because of the severe congestion in the city and its strategic economic importance to the nation, but also because of wider antiterrorist initiatives (see Coaffee, 2004). At a more microscale, major highways and motorways are much more likely to be surveyed and regulated through automated technologies than minor roads and residential streets. (Interestingly, these 'unwired' places in the assemblage have often been subject to alternate, physical traffic 'calming', the disciplining of drivers through 'dumb' road humps, chicanes, and width constrictions.) This is because volume of traffic needs to be regulated with regards to flow and tolls. In addition, there is an uneven application across drivers and vehicles. For example, depending on age and previous penalties drivers can be software-sorted with regards to insurance, finance for buying vehicles, and so on. Newer and more expensive vehicles are those that are more likely to be fullup with software within sophisticated engine management systems, GPS navigation tools, and so on.

Beyond, infrastructural unevenness, traditional forms of evasion still persist such as driving stolen vehicles, driving without tax and insurance, and using false plates. As a measure of this continuing un-governmentality of automobility, in England and Wales in 2003 there were 5,244,000 recorded motoring offences, including 2,223,000 speeding violations and 1,058,000 parking infractions (DfT, 2005, p. 145). Recent estimates put the extent of uninsured driving in the UK at one in twenty (DfT, 2004b). It is envisaged that routinised, wholesale capta gathering via ANPR and later EVI when coupled with routines that continuously cross-reference records will force unlicensed, uninsured and untaxed cars off the roads to a significant degree (ACPO, 2005; DfT, 2004b; HoC, 2004). Yet this work in Britain is to 
be self-funded by fine income generated, an acknowledgement that governmentality is partial (and needs to be partial in order to fund the system of governmentality!).

In addition, new forms of counter-measures are being devised through the use of technologies that provide tools to empower drivers to resist other aspects of governmentality. For example, GPS-enabled speed camera detectors that warn drivers when they are approaching the site of a camera. These are being complemented by protests against some technologies, such as the vocal anti-speed camera campaigns in the UK which has argued that employment of automated management is more about local revenue raising than improving road safety. There is also a community of car enthusiasts who rather than modeling the materiality of their vehicles are hacking into software hidden in the ECUs (Vespremi, 2004). By rewriting the code, they are maximising car performance. Hackers have also been interested in exploiting code elsewhere in the automobility assemblage - the most obvious being able to control traffic lights, setting them to green on approach using home-made (and illegal) 'traffic signal pre-emption devices' (Poulsen, 2005).

\section{Conclusion}

In this paper, we have documented the important ways in which software systems are being used to more effectively manage automobility through the increasingly automatic production of drivers and driving spaces. As detailed, road infrastructure is being virtualised through the embedding of digital, networked technologies that monitor and regulate traffic flow in real-time; effective movement of vehicles are increasingly reliant on diagnostic sensors and embedded ECUs to drive and software to second guess human behaviour and correct for 'errors'; and drivers are increasingly enveloped in a myriad of databases that verify their status and profile their driving habits. In short, road infrastructure, vehicles and drivers are becoming evermore reliant and caught up in digital, networked technologies and their associated information systems, to the extent that automobilities would be highly dysfunctional if any of the systems' fail. For example, city streets quickly become gridlocked if a integrated management system for controlling traffic lights crashes, as evidenced by failure of 800 traffic lights in July 2002 in London. At the start of the morning rush-hour a software update on Transport for London's SCOOT system failed leading to a loss of central co-ordination with lights having to fall back onto local sequencing patterns, which in turn led to significantly higher levels of congestion. $^{17}$

These new systems, we contend, are changing in radical ways the nature of governmentality with respect to auto-

\footnotetext{
${ }^{17}$ See "Gridlock as 800 London traffic lights seize", July 25, 2002, http:// catless.ncl.ac.uk/Risks/22.18.html\#subj1, and "Software crashes London traffic lights", July 24, 2002, http://news.zdnet.co.uk/software/0,39020381, $2119737,00$. htm.
}

mobilities through a process of automation, creating a system we have termed automated management. Here, the practice of regulation is transferred from electromechanical technologies that need manual supervision and processing to digital systems that use software algorithms to automatically process capta. As we have detailed, automated management consists of two interlocking sets of regulatory technologies: automated surveillance that seeks to enforce more effective (self)disciplining and capture systems that actively modulate activity and experience. These technologies work together to create hybrid systems of governmentality that are dynamic, work in real-time, and are exhaustive in their operation. As such, they work to shift governmentality from an oligoptical arrangement to a more panoptic one that is distributed across space and diffused among many institutional actors.

We argue that automated management works to alter the automobilities assemblage by creating new socio-spatial arrangements with respect to access, movement and flow, changing the conditions under which particular spaces, at particular times, are beckoned into being (see also Dodge and Kitchin, 2005b). Technologies such as ANPR monitoring, 'easy-pass' tags, and transponders regulate the access of vehicles to different parts of the automobilities network. GPS and telematics can be used to monitor a vehicle's position and movement precisely in space-time in real-time. Traffic management systems seek to manage the efficient flow of traffic across a road network. Automated surveillance systems (self)discipline, and vehicle management systems modulate how people experience driving around the road network.

A consequence of automated management then is the production of new spaces and subjects - novel socio-spatial processes and formations that are reliant on new sociotechnical systems. While some of these subjects and spaces are variants on longstanding modes, many are entirely new in the sense that were not previously possible and are reliant on new technologies and assemblages. Software makes a crucial difference to their production by enabling new automated processes to unfold in a variety of ways, some benign, some empowering, and some as agents of governmentality. The effect is the production of new automobilities, with future alternative productions inevitable given the pace of technological change and the desire of corporations and governments to derive further profit and enhance regulation. Moreover, given the widespread congestion affecting many cities and the need to improve the safety of road users new productions are necessary to stop the existing infrastructure from becoming gridlocked on a more regular basis. That said, as with previous modes of governmentality there are significant gaps, spatial unevenness and social inequality in its application. As a consequence, the automatic production of driving spaces varies across people and place.

While we, and others, have made a start to try and think through the socio-spatial implications of the application of software and distributed technologies to automobilities, 
there is clearly much more to done. In particular, there is a need to more fully tease out: how such technologies automatically produce space with respect to access, movement and flow, and how this affects the spatial behaviour of drivers through detailed case studies; the extent to which such productions are uneven, unequal and scaled from the local to the transnational; the socio-spatial implications of such productions with regards marginalisation, exclusion, privacy and the segmented geographies of travel, the differential geographies of (real and perceived) risk, and the unequal geographies of production and consumption; and the interrelationship between state and supra-state policy, commercial interests, community activism, individual resistance and evolving forms of automobilities and associated productions of space. This is challenging because while the material carapaces of capture systems are partially visible in terms of the detectors and input devices that harvest capta, the more important algorithms are internalised and invisible to observation and inaccessible to critical analysis (see also, Graham, 2005). That said, we think that such research will be a highly productive venture as vehicles increasingly become computers on wheels driving through virtualised landscapes by machine-readable drivers.

\section{References}

ACPO, 2005. ANPR strategy for the police service, 2005/2008. ACPO ANPR Steering Group, March. Available from: <www.acpo.police.uk/ asp/policies/Data/anpr_strat_2005-08_march05_12x04x05.doc>.

Agre, P.E., 1994. Surveillance and capture: two models of privacy. Information Society 10 (2), 101-127. Reprinted in: Wardrip-Fruin. N., Montfort, N. (Eds.), 2003. New Media Reader. MIT Press, Cambridge, MA, pp. $740-760$.

Austen, I., 2003. Your brake pads may have something to say (by email). The New York Times, March 27. Available from: <www.nytimes.com/ 2003/03/27/technology/circuits/27next.html>.

Baard, M., 2005. Brit license plates get chipped. Wired News, August 9. Available from: <www.wired.com/news/privacy/0,1848,68429,00.html>.

Becker, H., 1952. Science, culture, and society. Philosophy of Science 19 (4), 273-287.

Bennett, C., Raab, C., Regan, P., 2003. People and place: patterns of individual identification within intelligent transportation systems. In: Lyon, D. (Ed.), Surveillance as Social Sorting: Privacy, Risk and Digital Discrimination. Routledge, London, pp. 153-175.

Bunszel, C., 2002. Intelligent cars, intelligently. Electronic News, July 1. Available from: <www.reed-electronics.com/electronicnews/article/ CA189592>.

Coaffee, J., 2004. Rings of steel, rings of concrete and rings of confidence: designing out terrorism in central London pre and post September 11th. International Journal of Urban and Regional Research 28 (1), 201-211.

Curry, M.R., Philips, D.J., Regan, P.M., 2004. Emergency response systems and the creeping legibility of people and places. The Information Society $20,357-369$.

DfT, 2004a. Feasibility study of road pricing in the UK. Department for Transport, 20 July. Annex C: charging technologies and existing schemes. Available from: <www.dft.gov.uk/stellent/groups/dft_roads/ documents/divisionhomepage/029798.hcsp>.

DfT, 2004b. Uninsured driving in the UK. A report to the Secretary of State for Transport by Professor David Greenaway, University of Nottingham. Department for Transport. 11 August. Available from: $<\mathrm{http}: / /$ www.dft.gov.uk/stellent/groups/dft_roads/documents/page/dft_ roads_030393.hcsp>.

DfT, 2005. Transport Statistics Great Britain: 2005, Annual Report. Department for Transport, The Stationery Office, London.

Dodge, M., Kitchin, R., 2004. Flying through code/space: the real virtuality of air travel. Environment and Planning A 36 (2), 195-211.

Dodge, M., Kitchin, R., 2005a. Codes of life: identification codes and the machine-readable world. Environment and Planning D: Society and Space 23 (6), 851-881.

Dodge, M., Kitchin, R., 2005b. Code and the transduction of space. Annals of the Association of American Geographers 95 (1), 162-180.

Duvall, M., 2005. Software bugs threaten Toyota hybrids. Baseline Magazine, August 4. Available from: <http://www.baselinemage.com/ print_article2/0,1217,a $=157418,00$. asp $>$.

Elliot, C., 2004. Some rental cars are keeping tabs on the drivers. The New York Times, January 13. Available from: <www.nytimes.com/2004/01/ 13/business/13gps.html>.

Featherstone, M., 2004. Automobilities: an introduction. Theory, Culture and Society 21 (4-5), 1-24.

Foucault, M., 1976. Discipline and Punish. Allen Lane, London.

Foucault, M., 1978. The History of Sexuality (vol. 1). Random House, New York.

Gilbert, A., 2005. States to test ID chips on foreign visitors. CNET News.com, January 26. Available from: <http://news.com.com/21021039_3-5552120.html>.

Graham, S., 2005. Software-sorted geographies. Progress in Human Geography 29 (5), 562-580.

Haggerty, K., Ericson, R., 2000. The surveillant assemblage. British Journal of Sociology 51 (4), 605-622.

Higgs, E., 2001. The rise of the information state: the development of central state surveillance of the citizen in England, 1500-2000. Journal of Historical Sociology 14 (2), 175-197.

HoC, 2004. Cars of the Future, Seventeenth Report of Session 2003-2004 House of Commons Transport Committee (vol. I, HC319-I). The Stationery Office, London. Available from: <www.publications.parliament.uk/pa/cm200304/cmselect/cmtran/319/319.pdf>.

Jakle, J.A., Sculle, K.A., 2004. Lots of Parking: Land Use in a Car Culture. University of Virginia Press, Charlottesville, VA.

Kariatsumari, K., 2005. Packing more electronics into cars. Nikkei Electronics Asia, September. Available from: < http://neasia.nikkeibp.com/ neasiaarchivedetail/002049>

Kitchin, R., Dodge, M., 2006. Software and the mundane management of air travel. First Monday 7 (9). Available from: <www.firstmonday.org/ issues/special11_9/>

Lyon, D., 2003. Surveillance as social sorting: computer codes and mobile bodies. In: Lyon, D. (Ed.), Surveillance as Social Sorting: Privacy, Risk and Digital Discrimination. Routledge, London, pp. 13-30.

McNay, L., 1994. Foucault: A Critical Introduction. Polity Press, Oxford.

Oliver, M., 2004, They have your number. The Guardian, July 29. Available from: <www.guardian.co.uk/print/0,3858,4980979-105744,00.html>.

Poulsen, K., 2005. Traffic hackers hit red light. Wired News, August 12. Available from: <www.wired.com/news/autotech/0,2554,68507,00.html>.

PRNewswire, 2004. OnStar achieves another first as winner of Good Housekeeping's 'Good Buy' award for best service. December 3. Available from: $<$ http://finance.lycos.com/qc/news/story.aspx?story $=45410120>$.

Sheller, M., Urry, J., 2000. The city and the car. International Journal of Urban and Regional Research 24 (4), 737-757.

TfL, 2003. ITS in London: How intelligent transport systems are helping to get London moving. Transport for London. Available from: $<w w w . t r a n s p o r t f o r l o n d o n . g o v . u k /$ streets/pdfdocs/intelligent-transportsystems.pdf $>$.

Thrift, N., 2004. Driving in the city. Theory, Culture and Society 21 (4/5), $41-59$.

Thrift, N., French, S., 2002. The automatic production of space. Transactions of Institute of British Geographers NS 27, 309-325.

Vespremi, D., 2004. Car Hacks and Mods for Dummies. For Dummies Publishing, New York. 